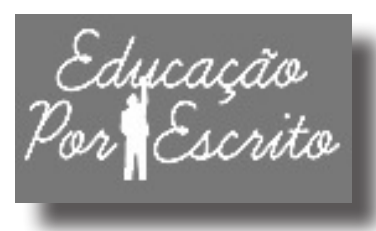

ARTIGO

\section{Editor}

Maria Inês Côrte Vitoria PUCRS, RS, Brasil

\section{Equipe Editorial}

Pricila Kohls dos Santos PUCRS, RS, Brasil

Marcelo Oliveira da Silva PUCRS, RS, Brasil

Carla Spagnolo PUCRS, RS, Brasil Rosa Maria Rigo PUCRS, RS, Brasil

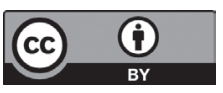

A matéria publicada neste periódico é licenciada sob forma de uma Licença Creative Commons - Atribuição 4.0 Internacional. http://creativecommons.org/licenses/by/4.0/

\title{
O programa de bolsas de incentivo à docência (PIBID) e a abordagem do ciclo das políticas: estabelecendo relações entre a formação de professores, a universidade e o contexto emergente
}

The fellowship program to encourage the teaching (PIBID) cycle approach and policies: setting relations between teacher education, university and emerging context

Michele Martelet ${ }^{\mathrm{a}}$ Marília Costa Morosinib

RESUMO: As discussões sobre a formação de professores, o processo de internacionalização dessas políticas e o contexto em que apresenta-se a Educação Superior vêm sugerindo novos rumos para essas temáticas em nível local/nacional/global. Diante disso, o objetivo deste trabalho é apresentar uma análise sobre o Programa de Bolsas de Incentivo à Docência (PIBID), promovendo uma aproximação com a abordagem do ciclo de Políticas e com as possíveis relações que ora surgem envolvendo essa política de formação de professores, a universidade e o contexto emergente. A relevância deste trabalho constitui-se a partir da abordagem do ciclo das políticas proposta por Ball e Bowe (1992), presente em Mainardes (2006), na tentativa de compreendermos com maior clareza as questões que envolvem o lócus de funcionamento do referido Programa, as novas diretrizes para as políticas públicas educacionais e a Educação Superior e, mais especificamente, o papel da universidade como instituição capaz de corroborar novas perspectivas, por meio de suas ações, para a educação no contexto emergente.

Palavras-chave: Formação de professores. Educação superior. Ciclo de políticas. PIBID. Contexto emergente.

ABSTRACT: Discussions of teacher education, the process of internationalization of these policies and context in which it is presented to the Higher Education is suggesting new directions for these issues in local/national/ global level. Therefore the aim of this project is to present an analysis of the Scholarship Program Teaching Incentive (PIBID), promoting an approach with the approach of the policy cycle and the possible relations that sometimes arise involving this policy of teacher education, the university and the emerging context. The relevance of this work is to approach from the proposed policies by Ball \& Bowe (1992), present in Mainardes (2006),

\footnotetext{
a Professora da rede municipal de Santa Maria/RS e mestre em educação pela Pontifícia Universidade católica do Rio Grande do Sul (PUCRS).<michelemartelet@yahoo.com.br>.
}

b Orientadora e professora do programa de pós-graduação em educação da PUCRS. <marilia.morosini@pucrs.br> 
in an attempt to understand with more clarity the issues surrounding the focus of operation of the program `s cycle, new guidelines for public education and higher education policy; and, more specifically, the role of the university as an institution able to corroborate the new perspectives, through their actions, for education in the emerging context.

Keywords: Teacher training; Higher education; Policy cycle; PIBID; Emerging context.

$\mathrm{D}$ iante do que pode ser apreciado no que se refere à Formação de professores e do que vem sendo discutido envolvendo esse contexto, evidenciamos uma estreita relação existente entre essa temática, o processo de internalização das políticas educacionais e a realidade que envolve a docência e a Educação Superior no Brasil.

Diante disso, o que observamos é a existência de um panorama no qual a Universidade vem delineando novos rumos que acompanham essas ações. Nessa perspectiva, há a constituição de um cenário atual, envolvendo as discussões e iniciativas a respeito do que é desenvolvido nesse nível de ensino no âmbito local/nacional/global. O olhar sobre tal perspectiva, a nosso ver, torna-se uma ferramenta cognitiva necessária e constitui uma composição possível, acompanhando a tendência em alcançar um ponto reflexivo sobre a realidade educativa em que vivemos.

Sendo assim, o objetivo deste trabalho é apresentar uma análise sobre o Programa de Bolsas de Incentivo à Docência (PIBID), promovendo uma aproximação com a abordagem do ciclo de Políticas e com as possíveis relações que ora surgem envolvendo essa política de formação (continuada) de professores, a universidade e o contexto emergente.

Nesse ínterim, temos os elementos que vão se delineando através das políticas educacionais e que, por esse motivo, também passam a compor o cenário ora descrito. Por política educacional, entendemos e corroboramos a definição de Akkari:

[...] Política educacional é um conjunto de decisões tomadas antecipadamente, para indicar as expectativas e orientações da sociedade em relação à escola. Uma política educacional visa assegurar a adequação entre as necessidades sociais de educação e os serviços prestados pelos sistemas educacionais por meio de três eixos principais: a) estabelecimento de regras e mecanismos de controle aos quais o sistema educacional deve se submeter; b) Incentivo de inovações educacionais pertinentes; c) garantia da gestão administrativa e financeira do sistema. (AKKARI, 2011, p. 12)

Para situar as discussões e reflexões que permearão este trabalho precisamos antever que as políticas educacionais, na atualidade, passam por um processo de internacionalização. Conforme afirma Akkari, 
o processo de internacionalização produz tensões nas políticas nacionais de educação tornando difícil a articulação entre as exigências nacionais (regionais e locais) e os imperativos internacionais (globais). Além disso, a divisão de responsabilidades entre os níveis nacional, regional e local também estão em plena reestruturação (VAN HAECHT, 1998). Temos a impressão de que muitos países se desobrigam da tomada de decisão em educação nos níveis global (internacional) e local (subnacional, regional) reduzindo, assim, o poder do estado nacional. (AKKARI , 2011, p. 15)

Ao acompanhar esse processo, o Ensino Superior também passa a (re)significar-se de diferentes formas em nível mundial. Dessa forma, a universidade é desafiada a propor, por meio de suas ações, a criação de novos projetos, programas e/ou outras parcerias participando desse movimento e intervindo na realidade educativa que também vai se redefinindo. Um desses programas, que passa a instituir-se como política pública para a formação de professores no Brasil, é o PIBID - Programa Institucional de Bolsas de Incentivo à Docência.

Desde 2010, esse Programa, que passou a vigorar com o decreto no 7.219 de 24 de junho da CAPES, vem a complementar um conjunto de ações desenvolvidas no Brasil que estão redefinindo a formação de professores e as políticas públicas nesse setor. O PIBID, dessa forma, surge como uma iniciativa para o aperfeiçoamento e a valorização da formação de professores da Educação Básica. Seus principais objetivos são:

- Incentivar a formação de docentes em nível superior para a educação básica;

- Contribuir para a valorização do magistério;

- Elevar a qualidade da formação inicial de professores nos cursos de licenciatura, promovendo a integração entre educação superior e educação básica;

- Inserir os licenciandos no cotidiano de escolas da rede pública de educação, proporcionando-lhes oportunidades de criação e participação em experiências metodológicas, tecnológicas e práticas docentes de caráter inovador e interdisciplinar que busquem a superação de problemas identificados no processo de ensinoaprendizagem;

- Incentivar escolas públicas de educação básica, mobilizando seus professores como conformadores dos futuros docentes e tornando-os protagonistas nos processos de formação inicial para o magistério; e

- Contribuir para a articulação entre teoria e prática necessárias à formação dos docentes, elevando a qualidade das ações acadêmicas nos cursos de licenciatura. (CAPES, 2010)

O Programa Institucional de Bolsas de Incentivo à Docência - PIBID da Coordenação de Aperfeiçoamento de Pessoal do Nível Superior - CAPES oferece bolsas a alunos dos cursos de licenciatura, aos professores das universidades que atuam nesses cursos e com professores de escolas da rede pública que atuam como supervisores 
no espaço escolar e que também integram esse programa. As instituições de Ensino Superior públicas ou privadas e sem fins lucrativos que desejam participar do programa devem inscrever seus projetos na CAPES, conforme edital publicado.

Ao serem aprovadas pela CAPES, as instituições recebem cotas de bolsas e recursos de custeio e capital para o desenvolvimento de atividades dos projetos inscritos. Quanto aos bolsistas, esses são escolhidos por meio de seleções promovidas por cada uma das IES que oferecem o PIBID.

Nesse contexto, o PIBID aparece no cenário local/nacional/global brasileiro como uma possibilidade para a discussão dos novos rumos das políticas públicas para a formação de professores. Assim sendo, justificamos a relevância deste trabalho a partir da abordagem do ciclo das políticas, proposta por Ball e Bowe (1992), presente em Mainardes (2006), na tentativa de compreender com maior clareza as questões que envolvem o lócus de funcionamento do referido Programa, as novas diretrizes para as políticas públicas educacionais e o Ensino Superior e, mais especificamente, o papel da universidade como instituição capaz de corroborar com a novas perspectivas, por meio de suas ações, para a educação no contexto emergente.

\section{$O$ contexto da influência}

O PIBID/CAPES teve seu funcionamento instituído a partir do ano de 2010, como já mencionamos anteriormente. O que compunha o cenário internacional e brasileiro, nessas últimas décadas, é o que pretendemos abordar nesse item, com o intuito de conhecermos e destacarmos as questões que tiveram relevância no contexto do surgimento do referido Programa.

No que diz respeito ao campo das políticas, percebemos que, a partir da última década do século XX, ocorreram diversos eventos e a participação sui generis de instituições internacionais como a Organização dos Estados Americanos (OEA), o Banco Interamericano do Desenvolvimento (BID), o Banco Mundial (BM), a Comunidade Europeia (CE), a Organização para a Cooperação e Desenvolvimento Econômico (OCDE) e o Programa das Nações Unidas para o Desenvolvimento (PNUD) com vistas a incentivarem o crescimento econômico dos países dos quais essas organizações faziam parte.

A lógica de mercado já instituída então na economia internacional, durante a década de 1990, passou a fazer parte das relações sociais, flexibilizando e precarizando os empregos. Isso teve influências e apareceu como uma característica nas reformas educativas ao propor o desenvolvimento de competências e habilidades, o monitoramento dos resultados dos alunos e a promoção da autonomia das escolas (RODRIGUEZ e VARGAS, 2008; OLIVEIRA, 2003). 
Destacamos também que a "Conferência Mundial sobre Educação para todos", em Jontiem, no ano de 1990, foi um marco das reformas educacionais elaboradas em nível mundial nos anos seguintes. Como diretrizes desse encontro houve a orientação aos países periféricos, segundo Mazzeo (2009), para aumentarem a taxa de escolaridade e erradicarem o analfabetismo não exagerando no aumento dos recursos financeiros e humanos. Além disso, Rodriguez e Vargas (2008) e Oliveira (2003) colocam que a orientação dada aos países durante o encontro era a de promover uma educação que garantisse maior equidade social, com foco na Educação Básica e nas questões docentes.

Em 2000, uma outra importante reunião, em Dakar, foi realizada com o intuito de avaliar os cumprimentos das metas e iniciativas da reunião realizada dez anos antes na Tailândia e de propor novas estratégias para a melhoria da qualidade da educação e do acesso a todos assegurando esse direito.Com base em dados analíticos, pesquisados em reuniões que aconteceram durante os anos de 1966 a 2002 por Rodriguez e Vargas (2008), é possível percebermos que no decorrer do encontro em Dakar as novas determinações estabelecidas centravam-se na elevação da qualidade profissional, com vistas à melhoria da condição social, do ânimo e da competência profissional.

No que se refere especificamente ao Ensino Superior, percebemos que com a conferência mundial sobre a Educação Superior (CMES), realizada em Paris, no ano de 1998, inicia-se um novo impulso para as discussões políticas que envolvem esse contexto. Nessa oportunidade, foi aprovada a "Declaração Mundial sobre o Ensino Superior para o século XXI: visão e ação" acompanhada de um plano de ação. Segundo Trumbic:

a estrutura conceitual de tal declaração foi embasada em um conjunto de medidas fundamentais: 1) Ampliação do acesso ao ensino superior como peça fundamental do desenvolvimento- entendida como um bem público e um direito humano; 2) A promoção de reformas da Educação Superior, nos níveis institucionais e organizacionais, visando aprimorar sua qualidade,pertinência e eficiência; 3) Garantir recursos e financiamentos suficientes - públicos e privados- para lidar com o aumento das demandas no ensino superior pelos seus diferentes públicos de interesse. (TRUMBIC, 2009, p. 16)

Tais diretrizes sinalizam para a expansão do Ensino Superior, e da Universidade enquanto instituição em nível mundial na qual o crescimento das matrículas mostrou-se significativo. No entanto, tal aumento distancia-se da realidade de economias desenvolvidas, cuja pretensão é oferecer acesso à sociedade do conhecimento. Isso implica o surgimento de um novo panorama para o Ensino Superior, que influencia o campo das políticas públicas no Brasil e em outras realidades mundiais denominado de contexto emergente, delineando novos futuros possíveis para os rumos desse nível de ensino. 
A caracterização do contexto emergente passa por diversos pontos. Sua origem contempla a mobilidade de uma série de elementos e questões que envolvem a universidade como um todo, suas leis, diretrizes, concepções teóricas, práticas e sociais que foram articulando-se no decorrer da história, entre o modelo tradicional de Educação Superior e o modelo neoliberal que constituiu-se com a globalização, em que há o ethos do desenvolvimento humano e social e a interação com outras visões de homem e sociedade.

Nesse novo contexto, a universidade passa agora a discutir e a redefinir seu papel, passando por realinhamentos de diversas ordens que passam a reestabelecer objetivos, teorias, práticas e direcionamentos de pesquisa. Com isso, há a sua realocação, ou seja, ela passa de centro autônomo de produção, transmissão e preservação do conhecimento a ser reconhecida como instituição que dimensiona socioculturalmente a construção sustentável do conhecimento. Corroborando com essa ideia, Teixeira coloca que:

Entendidas deste modo, as universidades têm de ser repensadas necessariamente no que respeita à estrutura do seu processo e práticas comunicativas. Se até agora, se tinha estruturado enquanto focos difusores de conhecimento, como transmissores de um conteúdo, numa perspectiva unidirecional de um para muitos, o deslocamento do centro comunicacional obriga a que as reposicionemos numa dinâmica de fluxo. Assim, as universidades deixam de ser emissoras de informação para se centrarem no tratamento da mesma. A sua missão deslocou-se pois da criação para o acrescento de valor. Às universidades cabe reciclar mais do que gerar, avaliar, validar, certificar a muita informação que flui nela e por ela. (TEIXEIRA, 2012, p. 3)

Assim sendo, a internacionalização percebida no Ensino Superior sugere novos elementos, os quais vão se constituindo e caracterizando a Universidade nestes novos tempos. Sobre isso, Bastos afirma que

há um crescente processo de internacionalização no ensino superior, com a mobilidade de estudantes e professores, da graduação ao pós-graduação, em programas de cooperação acadêmica, com apoio das agências de financiamento e pesquisa. Também há um estímulo à mobilidade acadêmica no âmbito nacional, especialmente de estudantes de graduação. Muitas instituições de Ensino Superior têm estabelecido alianças estratégicas com universidades de outros países, firmando convênios de cooperação acadêmica no ensino e na pesquisa. (BASTOS, 2013, p. 23)

Se por um lado, a universidade passa por renovações no campo epistemólogico, social, organizacional cultural e pedagógico tendo como principais motivadores as transformações que acompanham o contexto emergente, por outro, a política pública para a formação de professores igualmente é rediscutida e redefinida nesse sentido. 
Em meados dos anos 80, as principais discussões sobre a formação de professores eram motivadas por lutas e por reivindicações que sinalizavam para um novo tipo de currículo universitário, capaz de superar a racionalidade técnica ainda em vigor na época como consequência de políticas públicas educacionais dos anos 60 e 70, agregadas a possibilidade de unir ainda mais a categoria profissional tendo como bandeira de luta a valorização dos profissionais da educação e melhorias nas condições de salário e trabalho.

As novas ideias que se configuravam sobre a formação de professores, interferem, da mesma maneira, no Ensino Superior. Bastos caracteriza esse movimento da seguinte forma:

A partir do início da década de 1980, com a abertura gradual da política e o processo de redemocratização do país, uma nova constituição é aprovada e ocorre a primeira eleição direta em 1989. Com relação ao Ensino superior, a Constituição de 1988 lhe dedica poucos artigos. O artigo 207, lhe assegura 'autonomia didático-científica, administrativa e de gestão financeira e patrimonial, e obedecerão ao princípio de indissociabilidade entre ensino, pesquisa e extensão'. No parágrafo $2^{2}$ do inciso II do artigo 213, afirma-se que "as atividades universitárias de pesquisa e extensão poderão receber apoio do poder público. (BASTOS, 2013, p. 14-15)

Diante dessa composição política, econômica e social que se apresenta, envolvendo as questões que dizem respeito à educação mundial e ao papel do Ensino Superior, desde a última década do século XX até o momento atual, percebemos que as leis, decretos e normativas poderiam estar acompanhando esse movimento e influenciando os acontecimentos no âmbito educacional em diversos países. No item a seguir, propomo-nos a desvelar de que forma essas interferências ecoaram (ou não) na produção de normativas para a educação, em nível de Brasil.

\section{O contexto da produção do texto}

No Brasil, a repercussão dessas políticas educacionais, descritas anteriormente, que se delineavam em nível mundial, podem ser percebidas na concentração das questões colocadas em debate, especialmente a partir do texto da Lei de Diretrizes e Bases da Educação Nacional (LDB no 9394/96).

Com isso, constatamos que as reformas educacionais, que seguiram no final do século XX, acompanharam as tendências internacionais e o surgimento de novas preocupações por parte do governo tais como: aumentar a taxa de escolaridade, incentivar o acesso à educação, reduzir os índices de analfabetismo, formar professores em nível superior a baixos custos, dentre outros. 
Especificamente sobre a formação de professores, foco de análise deste trabalho, salientamos que as principais considerações dessa temática podem ser apreciadas fundamentalmente em dois documentos legais: a LDB/96, nos seus artigos 61 e 67, contidos no título VI referente à formação dos profissionais da educação; e as Diretrizes Curriculares Nacionais para a Formação de Professores (Parecer CNE/CP 9/2001 e Resolução CNE/CP 1/2002), em que menciona-se a formação dos professores pautada em competências.

Já colocada no âmbito da lei, a proposta inclusa sugere que a formação de professores vise, sobretudo, à adequação dessa formação aos modos de produção. Em decorrência disso, também foram incorporados jargões de âmbito administrativo-econômico à redação de propostas dentre as quais: "competência", "flexibilidade", "trabalho em equipe", "uso das tecnologias da informação" antes vistas principalmente em discursos empresariais. A repercussão dessa nova linguagem, que passa a fazer parte de textos e normativas, torna-se foco de estudo e de análise nessa época. Campos e Souza Junior (2011) corroboram essa perspectiva ao afirmarem que estudiosos da área educacional identificaram esse eixo em suas análises. Gatti e Barreto (2009), por exemplo, em um estudo realizado em diversos estados brasileiros, informam que os princípios norteadores da formação docente perpassam pela formação de competências, pela coerência entre prática e pesquisa e pelo foco no ensino e na aprendizagem. Em outra perspectiva, cujo enfoque nas competências foi objeto de um estudo minucioso realizado por Pereira (2008), questionou-se, contundentemente, o Parecer CNE/CP 9/2001 e a Resolução CNE/CP 1/2002, destacando os aspectos das competências na formação dos professores, que é segundo a autora uma adaptação dos sujeitos às exigências do capital.

No que tange à Formação Continuada, nesse contexto, a partir do que também colocam alguns estudiosos e pesquisadores dessas temáticas em âmbito global, há a tendência a agregá-las à profissionalização dos docentes apresentando-se como requisito para a melhoria da qualidade da educação enquanto processo para atingir seus objetivos para o século XXI. Assim, tais políticas apresentam-se fundamentadas no paradigma da sociedade do conhecimento no qual a educação torna-se, portanto, um imperativo, como sugere Delours (1998).

Essa preocupação contextualiza o entendimento de formação docente como resposta às exigências de titulação dos professores apresentando-se como possibilidade para o desenvolvimento da qualificação da educação pública. Assim, percebe-se uma tendência a investimentos, por parte do poder público, centrada em planos específicos ligados à profissionalização docente, vindo ao encontro da ideia de valorização dos profissionais que atuam na educação, especialmente no que se refere à remuneração e às condições de trabalho e carreira.

Essa nova realidade desenvolve um estado de mobilização, envolvendo universidades públicas e privadas, consórcios e diferentes arranjos institucionais acompanhada do entendimento de que essa seria a melhor estratégia para elevar a qualidade da educação básica. Os argumentos que endossam essa visão estão ligados a uma matriz que acredita que a formação docente, nesses moldes de eficiência, poderia suprir as dificuldades de aprendizagem dos 
alunos auxiliando, também, a elevar seu baixo rendimento. Tal visão restrita e, muitas vezes, focada no isolamento de outros fatores que poderiam intervir nesse processo traz como uma verdade a afirmação de que qualquer que seja a intervenção, em sala de aula, ela auxiliaria os professores a alcançarem objetivos e metas pré-estabelecidas.

Embora haja a tendência de países desenvolvidos em vincular a Formação Continuada à exigência do requisito de trabalho e como uma necessidade constante, tendo em vista as inconstâncias presentes na mudança dos conhecimentos, da tecnologia e do mundo do trabalho no Brasil, percebemos a pulverização de ações com uma demanda grande de iniciativas, não seguindo apenas uma única linha nos desenvolvimentos dessas atividades. Sobre isso, Gatti coloca que:

[...] a educação continuada foi colocada como aprofundamento e avanço nas formações dos profissionais. Incorporou-se essa necessidade também aos setores profissionais da educação, o que exigiu o desenvolvimento de políticas nacionais ou regionais em resposta a problemas característicos de nosso sistema educacional. (GATTI, 2008, p. 51)

Assim, as leis e normativas entram em sintonia com essas perspectivas. O decreto $\mathrm{n}^{\mathrm{o}}$ 6.755, de 29 de janeiro de 2009, trouxe a instituição da Política Nacional de Formação de Profissionais do Magistério da Educação Básica, outorgando as bases para a criação para o Plano Nacional de Formação de Professores da Educação Básica (PARFOR) junto à Coordenação de Aperfeiçoamento de Pessoal de Nível Superior (CAPES). O PARFOR é constituído de um conjunto de ações desenvolvidas pelo Ministério da Educação (MEC) em consonância com secretarias municipais e estaduais de ensino e as universidades públicas, que realizam cursos superiores e gratuitos e de qualidade para professores que atuam na Educação Básica, em instituições públicas, sem formação proposta pela LDB 9.394/96 na busca por atender o item que trata sobre a formação dos professores em nível superior para atuação no Ensino Fundamental.

Além desse decreto, o Plano Nacional de Professores da Educação Básica estabelece diretrizes para conduzir os processos de Formação, incluindo também a Continuada. Observamos que, contrariando a visão reducionista de continuidade no processo formativo dos professores, vinculado a questões materiais, salariais, diplomas, dentre outros, os centros de Ensino Superior, que agora apresentam-se engajados em uma nova proposta de superação dos principais desafios educacionais brasileiros, como formadores por excelência e encarregados também de estabelecer o fio condutor nesse processo de aperfeiçoamento, devem estar atentos à forma como pensam e posicionam seus currículos, projetos e atividades diante do que mostra-se constituído. 
As ações desenvolvidas, nessa perspectiva, vinculadas à formação de professores e ao estabelecimento de projetos e Programas desenvolvidos seriam uma alternativa para propor um contra ponto a essa lógica até então apresentada e a qual possui como possibilidade explorar, cada vez mais, a disseminação de práticas voltadas para atender as reais necessidades dos docentes e das realidades em que atuam na busca pela qualidade nesse processo.

Ainda nessa perspectiva, o decreto n⿳0 6.755/2009, que institui a Política Nacional de Formação de Profissionais do Magistério da Educação Básica, a CAPES - Coordenadoria de Capacitação de Pessoal do Nível Superior passa a ter a responsabilidade de incentivar programas de iniciação à docência em cursos de licenciatura, entre eles o PIBID - Programa Institucional de Bolsas de Incentivo à Docência. Em andamento desde o ano de 2010, o referido Programa tem apresentado, na prática, eficiência e algumas contribuições significativas no campo da formação inicial e continuada de professores. Esses aspectos abordamos a seguir.

\section{0 contexto da prática}

O PIBID/CAPES apresenta-se como um programa que tem por objetivo antecipar o vínculo entre os futuros professores, as salas de aula da rede pública e aqueles que já atuam com a formação continuada. A proposta visa criar uma inter-relação entre a educação superior (por meio dos cursos de licenciatura), as escolas e os sistemas estaduais e municipais de ensino.

Com ele, há a intenção de integrar as secretarias municipais e estaduais de ensino e as universidades públicas, e comunitárias, em favor da melhoria do ensino nas instituições de ensino públicas em que o índice de Desenvolvimento da Educação Básica (IDEB) estiver abaixo do nível nacional. Para a participação no Programa, os bolsistas recebem bolsas mensais. $\mathrm{O}$ valor da bolsa para os coordenadores de área do conhecimento (professores universitários) é de $\mathrm{R} \$ 1.200,00$; para os professores supervisores de escolas públicas que atuam em parceria com essa universidade e auxiliam na orientação dos alunos bolsistas, o valor da bolsa é de $\mathrm{R} \$ 765,00$; e para os alunos e acadêmicos dos cursos de licenciatura participantes do Programa, o valor da bolsa é de R\$465,00.

A instituição de ensino que demonstrar interesse em aderir ao Programa realiza a inscrição por meio de um edital que sugere a elaboração de uma proposta na forma de projeto. Podem participar do processo seletivo para esse edital instituições federais e estaduais de Ensino Superior, além de institutos federais de educação, ciência e tecnologia com cursos que apresentem avaliação satisfatória no sistema de Nacional de Avaliação da Educação Superior (SINAES).

Após a aprovação do Programa, a universidade passa a colocar em prática o seu projeto estruturado para o funcionamento do PIBID na instituição. Assim sendo, existem inúmeras possibilidades de implementação do Programa e da mesma forma há diferentes práticas referentes a ele sendo desenvolvidas em todo o país. 
Mesmo existindo uma diversidade bastante significativa de propostas e atividades sendo realizadas nas universidades, os relatos de trabalhos acadêmicos e os estudos já realizados por alguns pesquisadores sobre o PIBID têm revelado dois aspectos significativos que envolvem a prática das ações desenvolvidas por esse programa no que se refere à Formação Continuada dos professores participantes: a presença da pesquisa e a vivência da postura reflexiva diante da própria prática educativa.

Diante disso, percebe-se que na continuidade de sua formação o professor tem a oportunidade, como participante direta ou indiretamente do PIBID, de rever sua postura profissional com uma reflexão constante sobre seu exercício docente. SCHÖN (2000) caracteriza esse profissional pela disponibilidade constante em refletir sobre sua prática a fim de torná-la um instrumento articulador de saberes e habilidades, que servem para lidar com a complexa rede de elementos problematizadores que compõem a realidade educacional em que atuam. Colocando em contato a sua prática educativa e o modelo que dela serve aos acadêmicos participantes do programa na escola, o professor tem a oportunidade de exercitar a prática reflexiva sobre seu trabalho e, assim, revisitar suas ações educativas em busca de novas possibilidades que contribuam para seu desenvolvimento profissional.

Pensando sobre o conceito de "professor-reflexivo", e sobre as características de sua prática docente pautada na ação-reflexão-ação, podemos destacar que todo professor-reflexivo também é um professor-pesquisador, pois a necessidade da pesquisa surge a partir de questões levantadas sobre a problemática presente nas realidades observadas. Isso torna-se um elemento agregador de novas perspectivas quando discutimos a Formação Continuada de professores e seu desenvolvimento profissional no que se refere ao PIBID/CAPES.

Nesse sentido, reflexão e pesquisa estão intimamente relacionadas, porque possuem os mesmos princípios, enraizados e muito bem descritos por Freire quando coloca que "não há ensino sem pesquisa nem pesquisa sem ensino" (FREIRE, 1998, p. 32). Esse pesquisar, buscar e compreender criticamente só ocorrerá se o professor se propor a pensar sobre algo. Na redundância desse processo dialético em que se encontram pesquisa e reflexão, estão os conceitos que definem o professor-pesquisador e igualmente a necessidade do reconhecimento da temática como um saber necessário à prática educativa, o qual é oportunizado pela vivência no PIBID/CAPES.

\section{Considerações finais}

Diante do que nos propusemos a estudar e a refletir neste trabalho, é possível vislumbrarmos que o ciclo das políticas caracteriza-se como uma ferramenta de análise bastante significativa quando temos a pretensão de desmistificar e compreender elementos que se apresentam em uma dada realidade local/nacional/global. Através dela, temos contato com o contexto das questões que envolvem o estudo de temáticas propostas e, igualmente, 
com o seu aprofundamento, perpassando inclusive pela prática e por suas principais implicações no campo educacional.

Também foi possível percebermos que, embora sendo uma política para a formação de professores recente, o PIBID/CAPES possui aspectos vinculados à relevância da Universidade, como fomentadora de ações e iniciativas imersas no campo das políticas e Programas que desenvolve. Além disso, o Programa contribui para o atendimento das transformações que ocorrem envolvendo o Ensino Superior e suas novas características, frente ao contexto emergente, em um processo histórico constituinte. Com isso, por fim, constatamos que na prática o referido Programa tende a estabelecer relações com o contexto educativo e no lócus do Ensino Superior, apresentando elementos que estão para além do que está previsto nos objetivos dessa política tornando-se, dessa forma, uma experiência que contribui de maneira significativa para a formação de professores e para suas experiências individuais.

\section{Referências}

AKKARI, Abdeljalil. Internacionalização das Políticas Educacionais: transformações e desafios. Petrópolis: Vozes, 2011.

BALL, S.J.; BOWE, R. Subject departments and the "implementation" of National Curriculum policy: an overview of the issues. Journal of Curriculum Studies, London, v. 24, n. 2, p. 97-115, 1992. <http://dx.doi.org/10.1080/0022027920240201>.

BASTOS, Maria Helena Camara. O ensino superior no Brasil: um percurso histórico.in: VEIZLA, Cristinna (Org.). Historia de las universidades latinoamericanas: de la colonia a hoy. Córdoba: Universidad de Córdoba, 2013.

BRASIL. Senado Federal. Lei de Diretrizes e Bases da Educação Nacional, no 9.394/96. Brasília, 1996.

BRASIL. Decreto no 6.755, de 29 de janeiro de 2009. Institui a Política Nacional de Formação de Profissionais do Magistério da Educação Básica, disciplina a atuação da Coordenação de Aperfeiçoamento de Pessoal de Nível Superior - CAPES no fomento a programas de formação inicial e continuada, e dá outras providências. Diário Oficial [da República Federativa do Brasil], Brasília, DF, n. 21, 30 jan. 2009a. Seção I, p. 1-2. Disponível em: <http://www.planalto.gov.br/ccivil_03/Ato2007-2010/2009/Decreto/D6755. htm>. Acesso em: 28 out. 2013.

CAMPOS, Fernanda Araújo Coutinho; SOUZA JUNIOR, Hormindo Pereira. Políticas Públicas para a Formação de Professores: desafios atuais. Revista Trabalho \& Educação, Belo Horizonte, v. 20, n. 1, p. 33-46, jan.-abr. 2011.

COORDENAÇÃO DE APERFEIÇOAMENTO DE PESSOAL DE NÍVEL SUPERIOR - CAPES. Programa Institucional de Bolsas de Iniciação à Docência. 2010. Disponível em: <http://www.capes.gov.br/educacao-basica/capespibid>. Acesso em: 23 nov. 2013.

FREIRE, Paulo. Pedagogia da autonomia: saberes necessários à prática educativa. 7. ed. São Paulo: Paz e Terra, 1998.

GATTI, Bernardete A. Análise das políticas públicas para a formação continuada no Brasil, na última década. Revista Brasileira de Educação, v. 13, n. 37, jan.-abr. 2008. Disponível em: <http://www.scielo.br/pdf/rbedu/v13n37/06.pdf>. Acesso em: 12 jun. 2013. 
KUENZER, A. Z. A formação de educadores no contexto das mudanças no mundo do trabalho: novos desafios para as faculdades de educação. Educação e Sociedade, v. 19, n. 63, p. 105-125, ago. 1998.

MAINARDES, Jeferson. Abordagem do Ciclo de Políticas: uma contribuição para a análise de políticas educacionais. Revista Educação\&Sociedade, Campinas, v. 27, n. 94, jan.-abr. 2006. Disponível em: <http://www.cedes.unicamp.br>. Acesso em: out. 2013.

MAZZEU, L. T. B. A política de Formação docente no Brasil: fundamentos teóricos e metodológicos. In: REUNIÃO ANUAL DA ANPED, 32., 2009, Caxambu, MG. Anais... Caxambu, 2009.

PORTO, Claudio; RÉGNIER, Karla. O Ensino Superior no mundo e no Brasil - Condicionantes, tendências e cenários para o horizonte 2003-2025. MEC, 2003. Disponível em: <http://portal.mec.gov.br/sesu/arquivos/pdf/ensinosuperiormundobrasil tendenciascenarios2003-2025.pdf>. Acesso em: 28 out. 2013.

RODRIGUEZ, M. V.; VARGAS, M. B. A formação de professores na América Latina: um balanço dos debates nos fóruns internacionais 1966 - 2002. In: RODRIGUEZ, M. V.; VARGAS, M. B. (Org.). Políticas educacionais e formação de professores em tempos de globalização. Brasília: Liber Livro Editora/UCDB, 2008. p. 37-56.

SCHÖN, D. A. Educando o profissional reflexivo: um novo design para o ensino e a aprendizagem. Trad. Roberto Cataldo Costa. Porto Alegre: Artmed, 2000. 256 p.

TEIXEIRA, Antônio. Desconstruindo a universidade: Modelos universitários emergentes mais abertos, flexíveis e sustentáveis. RED, Revista de Educación a Distancia, n. 32, 30 sept. 2012. Disponível em: <http://www.um.es/ead/red/32>. Acesso em: 28 out. 2013.

TRUMBIĆ, Stamenka Uvalić. Unesco. In: MULLER, Vera (Trad.). Educação superior em um tempo de transformação: novas dinâmicas para a responsabilidade social. Porto Alegre: EDIPUCRS, 2009.

\section{Endereço para correspondência:}

Michele Martelet

Rua Jose Carnelosso, 90

97020-446 Santa Maria, RS, Brasil

<michelemartelet@yahoo.com.br>

Recebido em: maio/2014

Aceito em: dezembro/2014 